\title{
The Utilization of Physics Parameter to Classify Histopathology Types of Invasive Ductal Carcinoma (IDC) and Invasive Lobular Carcinoma (ILC) by using K-Nearest Neighbourhood (KNN) Method
}

\author{
Anak Agung Ngurah Gunawan ${ }^{1}$, I Wayan Supardi ${ }^{2}$, S. Poniman ${ }^{3}$, Bagus G. Dharmawan $^{4}$ \\ ${ }^{1,2,3}$ Physics Department, Udayana University, Bali, Indonesia \\ ${ }^{4}$ Radiology Department, Prima Medika Hospital, Bali, Indonesia
}

\begin{tabular}{l} 
Article Info \\
\hline Article history: \\
Received Jan 31, 2018 \\
Revised Apr 2, 2018 \\
Accepted Apr 20, 2018 \\
\hline
\end{tabular}

Keyword:

Invasive ductal carcinoma Invasive lobular carcinoma Nearest neighbourhood

\begin{abstract}
Medical imaging process has evolved since 1996 until now. The forming of Computer Aided Diagnostic (CAD) is very helpful to the radiologists to diagnose breast cancer. KNN method is a method to do classification toward the object based on the learning data which the range is nearest to the object. We analysed two types of cancers IDC dan ILC. 10 parameters were observed in 1-10 pixels distance in 145 IDC dan 7 ILC. We found that the Mean of $\mathrm{Hm}(\mathrm{yd}, \mathrm{d})$ at $1-5$ pixeis the only significant parameters that distingguish IDC and ILC. This parameter at 1-5 pixels should be applied in KNN method. This finding need to be tested in diffrerent areas before it will be applied in cancer diagnostic.
\end{abstract}

Copyright $(2018$ Institute of Advanced Engineering and Science. All rights reserved.

Corresponding Author:

Anak Agung Ngurah Gunawan

Departement of Physics,

Udayana University,

Bali, Indonesia.

Email: ngurah_gunawan@unud.ac.id

\section{INTRODUCTION}

The diagnosing of early breast cancer is very important to reduce the mortality rate for women. The breast cancer is the health problem in the world, many women die because of it. Most of the patients who come to have treatment have had advanced stage. Therefore, the early detection of breast cancer and its treatment is the only way to survive longer and to improve the patients' life quality. CAD system that is evolved is very helpful in diagnosing breast cancer. Besides, CAD system can also be used as the comparison of diagnostic result of the radiologists and the pathology and anatomy specialist doctors. In this kind of CAD system, the accuracy of result is very important. A misguided detection can cause a misguided treatment too. Because the problem is sensitive, there are many researchers do the research in breast cancer specialty and compete each other to achieve the better result.

The technologies developed all this time to detect early breast cancer are Ultrasonography (USG) device [1], [2], Mammography, Magnetic Resonance Imaging (MRI) [4], [5], and Positron Emission Tomography (PET) Scan [6]. All early detection tools above are unable to classify IDC and ILC histopathology types. Therefore, we propose a new technique to classify IDC and ILC histopathology types by using physics parameter as the input variable by using KNN method. Software that we produced would be planted in Mammography tool so that it could improve its activity as an early detection of breast cancer.

The research that we proposed was focused on mammogram images from Dokter Soetomo (Surabaya, Indonesia) Hospital, Sanglah (Denpasar, Bali, Indonesia) Hospital, and from Prima Medika 
(Denpasar, Bali, Indonesia) Hospital producing classification of IDC and ILC histopathology types. IDC was currently categorized into invasive carcinoma of no special type was terrace breast carcinoma, namely it was from $45 \%$ to $75 \%$ case, whereas ILC was only from 5 to $15 \%$ invasive breast carcinoma [7]. The disparity between these two types was clinicopathology characteristic and response regarding systemic therapy [8]. IDC Histopathology gave the growth image of invasive epithelium malignant cells which mostly form solid and sinsisial patterns, and part with glandular and tubules differentiation. ILC consists of epithelium malignant cells arranged in the spreading of individual cell or arranged in infiltrative linear pattern between fibrus connective tissue stroma and it was usually connected with lobular carcinoma in situ (LCIS) [7].

In our paper, we proposed a new method to classify histopathology types of ILC and IDC breast cancers. Because of the physics parameter value range of ILC and IDC was different [9]. So, physics parameter containing on the mammogram could be used as the input variable for KNN method to determine whether it belonged to ILC or IDC types.

The superiority of the method that we proposed was the output of our method was numerical form which its value was certainly to be very objective, it was different with the previous method that still used the visual reading which the result was very subjective and depending on the readers. Why did we do the research? We wanted to help decreasing the mortality rate of women who have had breast cancer.

The aim of the writing is to introduce a new method to detect the types of IDC and ILC histopathology. CAD system that we have developed is used as the comparison of FNAB result before doing the operation.

\section{METHODS}

\subsection{Sample}

The research was approved by ethics committee of Sanglah Hospital, Denpasar, Bali, Indonesia. Number: 1204/UN.14.2/KEP/2017. The samples were taken at random from the year 2013 to the year 2017 from the database of Dokter Soetomo Hospital (Surabaya, Indonesia), Prima Medika Hospital (Denpasar, Bali, Indonesia), Sanglah General and Central Hospital (Denpasar, Bali, Indonesia). The samples consisted of 7 images of ILC type and 145 images of IDC type.

\subsection{Developed method}

Gunawan [9] used physics parameter to determine histopathology types of breast cancer by using Special Pattern Cropping method. In this research, we developed the use of physics parameter as the input of KNN method to determine histopathology type of breast cancer.

It has been observed that the abnormality, especially the suspicious are with the higher density than the neighbor pixel like on the Figure 1 and Figure 2. We counted 9 physics parameters like entropy, contrast, angular second moment, inverse difference moment, mean of $\mathrm{Hm}(\mathrm{y}, \mathrm{d})$, deviation, entropy of $\mathrm{H}_{\text {diff, angular }}$ second moment of Hdiff and mean of $\mathrm{H}_{\text {diff }}$ for every pixel with the range between pixels from 1 pixel to 10 pixels. By using Anova statistics to get significant parameter that was able to distinguish IDC and ILC histopathology types. Then, we used chosen physics parameter as input variable from KNN method to take the final decision. We applied the pre-processing steps at the early algorithm to fix the image quality. The aim of repairing application of image quality was to clarify the image on mammogram. The block diagram explaining the method used was showed on Figure 3.

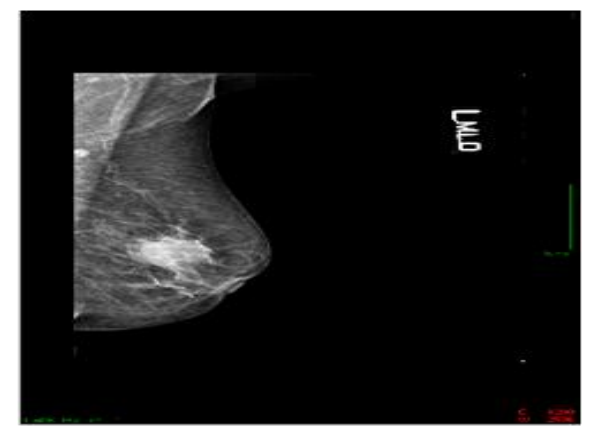

(a)

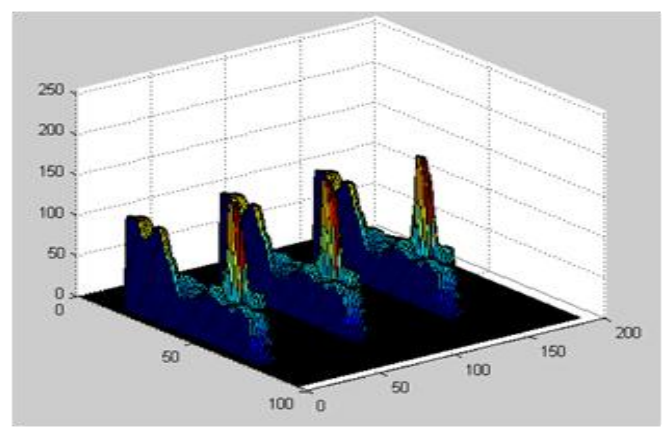

(b)

Figure 1. (a) IDC, (b) Subtract the background image of the original image Image: From the data base of Radiology Department of RSUP. Dr. Soetomo Surabaya Hospital. 


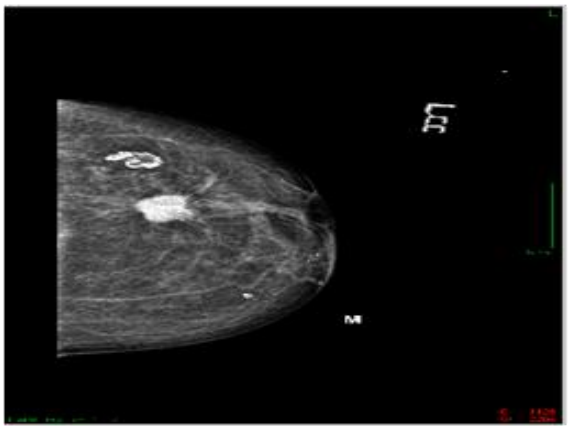

(a)

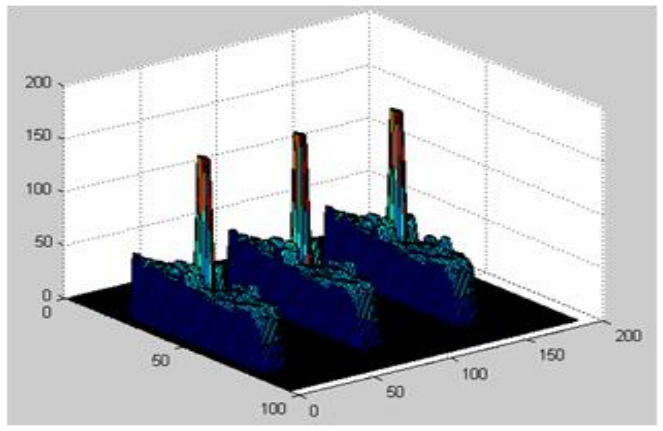

(b)

Figure 2. (a) ILC, (b) Subtract the background image of the original image Image: From the data base of Radiology Department of RSUP. Dr. Soetomo Surabaya Hospital.

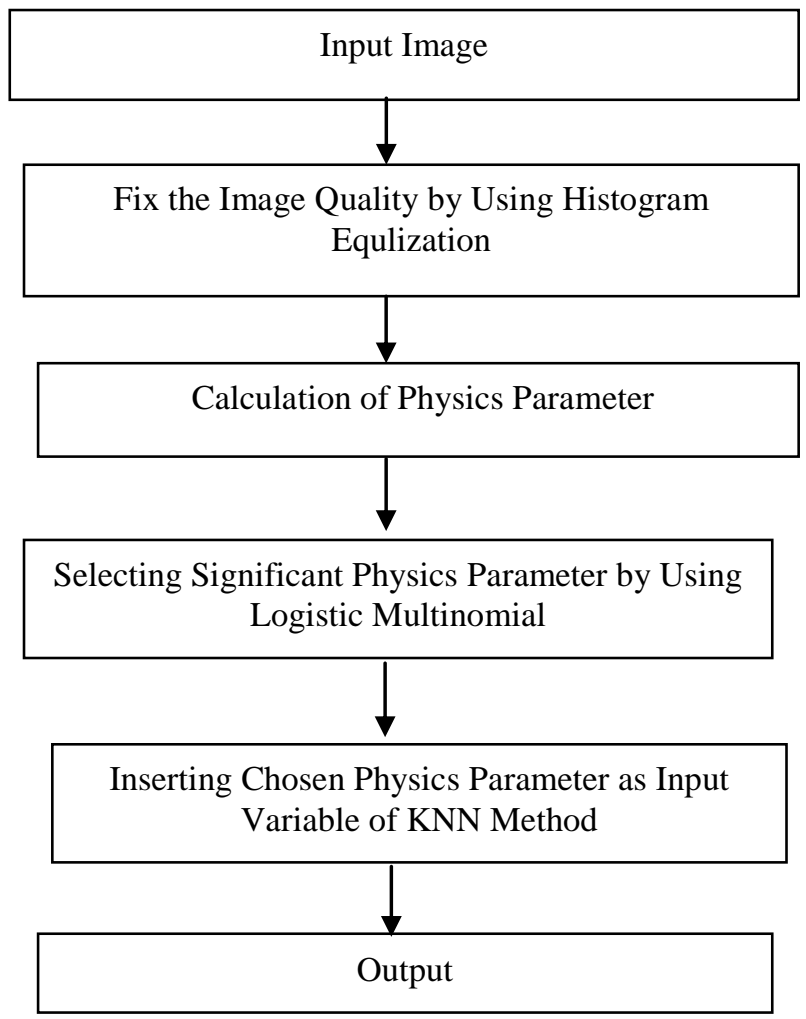

Figure 3. The steps of proposed algorithm

\subsection{Processing}

The aim of Processing step is to group mammogram images of ILC and IDC taken from the anatomic Pathologic research as the standard goal. Cropping the suspicious area. Then, it is done the reparation of the image quality to clarify the mammogram image.

\subsection{The calculation of physics parameter}

After the processing step, our algorithm counts 9 physics parameters, namely entropy, contrast, angular second moment, inverse differential moment, mean, deviation, entropy of Hdiff, angular second moment of Hdiff and mean of Hdiff at the range from 1 pixel to 10 pixels by using the Equations (1)-(13). The counted entropy from the histogram of order two provides the measurement of irregularity and defined like Equation (1). Histogram of order 2 illustrates the distribution of possibilities from the event of the pair of gray-level. 


$$
\begin{aligned}
& \text { Entropy }(E)=-\sum_{y_{q}=y_{1}}^{y_{t}} \sum_{y_{r}=y_{1}}^{y_{t}}\left[H\left(y_{q}, y_{r}, d\right)\right] \log \left[H\left(y_{q}, y_{r}, d\right)\right] \\
& \text { Contrast }(C)=\sum_{y_{q}=y_{1}}^{y_{t}} \sum_{y_{r}=y_{1}}^{y_{t}}\left(y_{q}-y_{r}\right)^{2} H\left(y_{t}, y_{r}, d\right) \\
& \text { Angular Second Moment }(\mathrm{MA})=\sum_{y_{q}=y_{1}}^{y_{t}} \sum_{y_{r}=y_{1}}^{y_{t}}\left[H\left(y_{q}, y_{r}, d\right)\right]^{2} \\
& \text { Momen Differensial Invers }(M D)=\sum_{y_{q}=y_{1}}^{y_{t}} \sum_{y_{r}=y_{1}}^{y_{t}}\left[\frac{H\left(y_{q}, y_{r}, d\right)}{1+\left(y_{q}-y_{r}\right)^{2}}\right]
\end{aligned}
$$

for $\mathrm{y}_{\mathrm{r}} \neq \mathrm{y}_{\mathrm{q}}$

$$
\text { Correlation (Corr) }=\frac{\sum_{y_{q}=y_{1}}^{y_{t}} \sum_{y_{r}=y_{1}}^{y_{t}} y_{q} y_{r} H\left(y_{q}, y_{r}, d\right)-\mu H_{m}\left(y_{q}, d\right) \mu H_{m}\left(y_{r}, d\right)}{\sigma H_{m}\left(y_{q q}, d\right) \sigma H_{m}\left(y_{r}, d\right)}
$$

with

$$
\begin{aligned}
& H_{m}\left(y_{q}, d\right)=\sum_{y_{r}=y_{1}}^{y_{t}} H\left(y_{q}, y_{r}, d\right) \\
& H_{m}\left(y_{r}, d\right)=\sum_{y_{q}=y_{1}}^{y_{t}} H\left(y_{q}, y_{r}, d\right) \\
& \text { Mean }(M N)=\sum_{y_{q}=y_{1}}^{y_{t}} y_{q} H_{m}\left(y_{q}, d\right) \\
& \text { Deviation }(D)=\sqrt{\sum_{y_{q}=y_{1}}^{y_{t}}\left[y_{q}-\sum_{y_{p}=y_{1}}^{y_{t}} y_{p} H_{m}\left(y_{p}, d\right)\right]^{2} H_{m}\left(y_{q}, d\right)} \\
& H_{\text {diff }}(i, d)=\sum_{y_{q}=\left|y_{q}-y_{r}\right|=i}^{y_{t}} \sum_{y_{r}=y_{1}}^{y_{t}} H\left(y_{q}, y_{r}, d\right) \\
& \text { Entropy of } H_{\text {diff }}(E H)=-\sum_{i=i_{1}}^{i_{t}} H_{\text {diff }}(i, d) \log H_{\text {diff }}(i, d) \\
& \text { AngularMoment of } H_{\text {diff }}(M A H)=\sum_{i=i_{1}}^{i_{t}}\left[H_{\text {diff }}(i, d)\right]^{2} \\
& \text { Mean of } H_{\text {diff }}(M H D)=\sum_{i=i_{1}}^{i_{t}} i H_{\text {diff }}(i, d)
\end{aligned}
$$

With $\mathrm{H}\left(\mathrm{y}_{\mathrm{q}}, \mathrm{y}_{\mathrm{r}}, \mathrm{d}\right), \mathrm{d}$, $\mathrm{y}$ each is the probability of a pair of gray-level, the distance between the pixel and gray level value, respectively [10], [11].

\subsection{The selection of physics variable}

Selection of significant physics variables as input KNN method that is able to distinguish type IDC and ILC using T test statistical analysis. The main reason why we used KNN method to determine invasive lobular carcinoma and invasive ductal carcinoma in breast cancer, because the categorization based on the nearest range between examined data with learning data used the Euclidean Distance formula like the Equation (14).

\subsection{KNN method}

KNN method is a method to do classification toward the object based on the learning data which the range is nearest to the object.

To calculate Euclidean Distance by using the Equation (14).

$$
D=\sqrt{\sum_{i=1}^{i=n}\left(T_{i}-U_{i}\right)^{2}}
$$

It consists of 2 input variables, namely mean 1 and mean 2 and 2 histopathology types, namely ILC and IDC. If there is a new data with mean1 value 180.81088 and mean2 $=181.11186$, is like Table 1 . 
Table 1. Mean1 and Mean2 and 2 Histopathology Types

\begin{tabular}{rrr}
\hline \multicolumn{1}{c}{ Mean1 } & \multicolumn{1}{c}{ Mean2 } & Type of Histopathology \\
\hline 114.26825 & 113.97313 & IDC \\
91.31764 & 91.71834 & IDC \\
150.37279 & 151.51907 & IDC \\
142.07158 & 142.72827 & IDC \\
155.47071 & 156.30185 & IDC \\
159.96244 & 161.16492 & ILC \\
149.01149 & 148.98700 & ILC \\
153.83340 & 153.93231 & ILC \\
149.59902 & 149.84301 & ILC \\
161.06060 & 161.83271 & ILC \\
\hline
\end{tabular}

The Steps:

1. Determine k parameter $=$ the nearest neighbor number. For instance $\mathrm{k}=3$.

2. Calculate the range between a new data and a learning data, is like Table 2.

Table 2. Range Between a New Data and a Learning Data

\begin{tabular}{lll}
\hline Mean1 & Mean2 & The range quadrate with the new data $(180.81088,181.11186)$ \\
\hline 114.26825 & 113.97313 & $(114.26825-180.81088)^{2}+(113.97313-181.11186)^{2}=8935.530673$ \\
91.31764 & 91.71834 & $(91.31764-180.81088)^{2}+(91.71834-181.11186)^{2}=16000.24142$ \\
150.37279 & 151.51907 & $(150.37279-180.81088)^{2}+(151.51907-181.11186)^{2}=1802.210543$ \\
142.07158 & 142.72827 & $(142.07158-180.81088)^{2}+(142.72827-181.11186)^{2}=2974.033346$ \\
155.47071 & 156.30185 & $(155.47071-180.81088)^{2}+(156.30185-181.11186)^{2}=1257.660812$ \\
159.96244 & 161.16492 & $(159.96244-180.81088)^{2}+(161.16492-181.11186)^{2}=832.5378658$ \\
149.01149 & 148.98700 & $(149.01149-180.81088)^{2}+(148.98700-181.11186)^{2}=2043.207834$ \\
153.83340 & 153.93231 & $(153.83340-180.81088)^{2}+(153.93231-181.11186)^{2}=1466.512365$ \\
149.59902 & 149.84301 & $(149.59902-180.81088)^{2}+(149.84301-181.11186)^{2}=1951.921185$ \\
161.06060 & 161.83271 & $(161.06060-180.81088)^{2}+(161.83271-181.11186)^{2}=761.7591848$ \\
\hline
\end{tabular}

3. The range order and the determination of the nearest neighbor based on the k minimum, is like Table 3.

Table 3. Determination of the Nearest Neighbor Based on the k Minimum

\begin{tabular}{|c|c|c|c|c|}
\hline Mean1 & Mean2 & $\begin{array}{l}\text { The range quadrate with the new data (180.81088, } \\
181.11186)\end{array}$ & $\begin{array}{l}\text { Minimum } \\
\text { range } \\
\text { level }\end{array}$ & $\begin{array}{c}\text { Including the } \\
\text { nearest } \\
\text { neighbor }\end{array}$ \\
\hline 114.26825 & 113.97313 & $\begin{array}{l}(114.26825-180.81088)^{2}+(113.97313-181.11186)^{2} \\
=8935.530673\end{array}$ & 9 & IDC \\
\hline 91.31764 & 91.71834 & $\begin{array}{l}(91.31764-180.81088)^{2}+(91.71834-181.11186)^{2} \\
=16000.24142\end{array}$ & 10 & IDC \\
\hline 150.37279 & 151.51907 & $\begin{array}{l}(150.37279-180.81088)^{2}+(151.51907-181.11186)^{2} \\
=1802.210543\end{array}$ & 5 & IDC \\
\hline 142.07158 & 142.72827 & $\begin{array}{l}(142.07158-180.81088)^{2}+(142.72827-181.11186)^{2} \\
=2974.033346\end{array}$ & 8 & IDC \\
\hline 155.47071 & 156.30185 & $\begin{array}{l}(155.47071-180.81088)^{2}+(156.30185-181.11186)^{2} \\
=1257.660812\end{array}$ & 3 & IDC \\
\hline 159.96244 & 161.16492 & $\begin{array}{l}(159.96244-180.81088)^{2}+(161.16492-181.11186)^{2} \\
=832.5378658\end{array}$ & 2 & ILC \\
\hline 149.01149 & 148.98700 & $\begin{array}{l}(149.01149-180.81088)^{2}+(148.98700-181.11186)^{2} \\
=2043.207834\end{array}$ & 7 & ILC \\
\hline 153.83340 & 153.93231 & $\begin{array}{l}(153.83340-180.81088)^{2}+(153.93231-181.11186)^{2} \\
=1466.512365\end{array}$ & 4 & ILC \\
\hline 149.59902 & 149.84301 & $\begin{array}{l}(149.59902-180.81088)^{2}+(149.84301-181.11186)^{2} \\
=1951.921185\end{array}$ & 6 & ILC \\
\hline 161.06060 & 161.83271 & $\begin{array}{l}(161.06060-180.81088)^{2}+(161.83271-181.11186)^{2} \\
=761.7591848\end{array}$ & 1 & ILC \\
\hline
\end{tabular}

From the three levels, ILC histopathology type comes out two times, whereas IDC comes out one, it means mean 1 value $=180.81088$ and mean $2=181.11186$ including ILC group . 


\section{RESULTS AND DISCUSSION}

Table 4 shows the average of physics parameter of idc and ilc at various distance (pixels) at Dr Sutomo Hospital Surabaya at 2017.

Table 4. Average of Physics Parameter of IDC and ILC at various distance (pixels) at Dr Sutomo Hospital Surabaya at 2017

\begin{tabular}{|c|c|c|c|c|c|c|c|c|}
\hline & \multirow[t]{2}{*}{ Pixel } & \multicolumn{3}{|c|}{$\begin{array}{c}\text { IDC } \\
(n=148)\end{array}$} & \multicolumn{3}{|c|}{$\begin{array}{c}\text { ILC } \\
(\mathrm{n}=7)\end{array}$} & \multirow[t]{2}{*}{$\begin{array}{l}\text { Signifi } \\
\text { kansi }\end{array}$} \\
\hline & & Average & $\begin{array}{l}\text { Standart } \\
\text { deviation }\end{array}$ & Standart error & Average & $\begin{array}{l}\text { Standart } \\
\text { deviation }\end{array}$ & Standart error & \\
\hline \multirow[t]{10}{*}{ Entropy } & 1 & 3.6104536 & 0.15085807 & 0.01252808 & 3.6171657 & 0.08066793 & 0.03048961 & 0.907 \\
\hline & 2 & 3.6568468 & 0.15332612 & 0.01273304 & 3.6617500 & 0.07960890 & 0.03008933 & 0.933 \\
\hline & 3 & 3.6777772 & 0.15452700 & 0.01283277 & 3.6813429 & 0.07883346 & 0.02979625 & 0.952 \\
\hline & 4 & 3.6885450 & 0.15457833 & 0.01283703 & 3.6888114 & 0.07873740 & 0.02975994 & 0.996 \\
\hline & 5 & 3.6947606 & 0.15360226 & 0.01275597 & 3.6952657 & 0.07904419 & 0.02987590 & 0.993 \\
\hline & 6 & 3.6949498 & 0.15554954 & 0.01291769 & 3.6998771 & 0.07793913 & 0.02945822 & 0.934 \\
\hline & 7 & 3.6982033 & 0.15187368 & 0.01261242 & 3.7000300 & 0.07765963 & 0.02935258 & 0.975 \\
\hline & 8 & 3.6965695 & 0.15078884 & .01252233 & 3.6977043 & 00.07783147 & 0.02941753 & 0.984 \\
\hline & 9 & 3.6941683 & 0.14933956 & 0.01240198 & 3.6966014 & 0.07457322 & 0.02818603 & 0.966 \\
\hline & 10 & 3.6909294 & 0.14800686 & 0.01229130 & 3.6916357 & 0.07334534 & 0.02772193 & 0.990 \\
\hline \multirow[t]{10}{*}{ Contras } & 1 & 315.1388486 & 177.70143713 & 14.75730112 & 339.7269071 & 251.49710240 & 95.05696977 & 0.726 \\
\hline & 2 & 499.2650374 & 300.94027582 & 24.99172961 & 552.7721929 & 479.90755321 & 181.38800544 & 0.656 \\
\hline & 3 & 656.7864110 & 395.39781826 & 32.83600155 & 569.0755014 & 489.84205140 & 185.14289281 & 0.937 \\
\hline & 4 & 801.8035399 & 484.31155031 & 10.21988509 & 779.0552014 & 512.88993163 & 193.85417272 & 0.904 \\
\hline & 5 & 937.9186496 & 571.04196611 & 17.42245409 & 385.5693447 & 553.34877610 & 209.14617855 & 0.813 \\
\hline & 6 & 1063.7877057 & 653.23207514 & 54.24797114 & 788.7686614 & 599.97791773 & 226.77033749 & 0.766 \\
\hline & 7 & 1181.3326292 & 732.63307678 & 50.84186542 & 1085.7139914 & 549.32149292 & 245.42045588 & 0.735 \\
\hline & 8 & 1291.0414610 & 809.84046662 & 57.25359016 & 1177.5454200 & 701.23899871 & 265.04342860 & 0.716 \\
\hline & 9 & 1396.3682258 & 889.44363204 & 73.86427323 & 1264.6367414 & 758.53064057 & 286.69763383 & 0.701 \\
\hline & 10 & 1494.5215899 & 966.88745656 & 30.29563279 & 1347.9700171 & 813.56216396 & 307.49759456 & 0.694 \\
\hline Anguler & 1 & 0.0003488 & 0.00015695 & 0.00001303 & 0.0003714 & 0.00017102 & 0.00006464 & 0.711 \\
\hline second & 2 & 0.0002964 & 0.000012514 & 0.00001039 & 0.0002857 & 0.00005593 & 0.00002114 & 0.823 \\
\hline \multirow[t]{8}{*}{ moment } & 3 & 0.0002806 & 0.00012200 & 0.00001013 & 0.0002714 & 0.00005146 & 0.00001945 & 0.843 \\
\hline & 4 & 0.0002726 & 0.00012036 & 0.00001000 & 0.0002643 & 0.00005062 & 0.00001913 & 0.857 \\
\hline & 5 & 0.0002673 & 0.00011942 & 0.00000992 & 0.0002614 & 0.00005146 & 0.00001945 & 0.897 \\
\hline & 6 & 0.0002639 & 0.00011959 & 0.00000993 & 0.0002571 & 0.00004786 & 0.00001809 & 0.883 \\
\hline & 7 & 0.0002623 & 0.00011742 & 0.00000975 & 0.0002571 & 0.00004786 & 0.00001809 & 0.909 \\
\hline & 8 & 0.0002616 & 0.00011728 & 0.00000974 & 0.0002571 & 0.00004786 & 0.00001809 & 0.921 \\
\hline & 9 & 0.0002619 & 0.00011727 & 0.00000974 & 0.0002571 & 0.00004192 & 0.00001584 & 0.916 \\
\hline & 10 & 0.0002629 & 0.00011695 & 0.00000971 & 0.0002571 & 0.00004192 & 0.00001584 & 0.897 \\
\hline Invers & 1 & 0.0547979 & 0.01312559 & 0.00109002 & 0.0520400 & 0.00878544 & 0.00332058 & 0.584 \\
\hline differensia & 2 & 0.0473543 & 0.03097366 & 0.00257222 & 0.0437914 & 0.00605996 & 0.00229045 & 0.762 \\
\hline \multirow[t]{8}{*}{1 moment } & 3 & 0.0401514 & 0.01083754 & 0.00090001 & 0.0385729 & 0.00577497 & 0.00218273 & 0.703 \\
\hline & 4 & 0.0384927 & 0.02187408 & 0.00181654 & 0.0361086 & 0.00613606 & 0.00231921 & 0.775 \\
\hline & 5 & 0.0344490 & 0.01014603 & 0.00084258 & 0.0340371 & 0.00624037 & 0.00235864 & 0.916 \\
\hline & 6 & 0.0326346 & 0.00972193 & 0.00080736 & 0.0323700 & 0.00596515 & 0.00225461 & 0.943 \\
\hline & 7 & 0.0310297 & 0.00974142 & 0.00080898 & 0.0312786 & 0.00615010 & 0.00232452 & 0.947 \\
\hline & 8 & 0.0296746 & 0.00940930 & 0.00078140 & 0.0299643 & 0.00546359 & 0.00206504 & 0.936 \\
\hline & 9 & 0.0285969 & 0.00945333 & 0.00078506 & 0.0285969 & 0.00945333 & 0.00078506 & 0.930 \\
\hline & 10 & 0.0276533 & 0.00925452 & 0.00076855 & 0.0279657 & 0.00546788 & 0.00206666 & 0.930 \\
\hline Mean of & 1 & 133.5669281 & 27.19744514 & 2.25862488 & 154.4756100 & 16.19232902 & 6.12012510 & 0.046 \\
\hline \multirow[t]{9}{*}{$\mathrm{Hm}(\mathrm{y}, \mathrm{d})$} & 2 & 133.9853676 & 27.26778725 & 2.26446648 & 154.9300529 & 16.22254719 & 6.13154650 & 0.046 \\
\hline & 3 & 134.3513773 & 27.32300711 & 2.26905224 & 155.2295157 & 16.21027822 & 6.12690927 & 0.047 \\
\hline & 4 & 134.6905923 & 27.37766341 & 2.27359120 & 155.4813714 & 16.17205405 & 6.11246189 & 0.049 \\
\hline & 5 & 135.0195647 & 27.41287327 & 2.27651522 & 155.6828743 & 16.11552700 & 6.09109667 & 0.050 \\
\hline & 6 & 135.3111239 & 27.45034260 & 2.27962687 & 155.8540200 & 16.07657784 & 6.07637527 & 0.052 \\
\hline & 7 & 135.5660110 & 27.48385842 & 2.28241021 & 156.0133371 & 16.08660616 & 6.08016562 & 0.053 \\
\hline & 8 & 135.8055795 & 27.49340697 & 2.28320317 & 156.1406957 & 16.10091118 & 6.08557241 & 0.055 \\
\hline & 9 & 136.0024805 & 27.52114376 & 2.28550659 & 156.2764029 & 16.13230995 & 6.09744003 & 0.056 \\
\hline & 10 & 136.1667878 & 27.54103176 & 2.28715820 & 156.4100486 & 16.18074467 & 6.11574663 & 0.056 \\
\hline \multirow[t]{10}{*}{ Deviation } & 1 & 31.6089927 & 10.37731414 & 0.86178903 & 31.2089386 & 8.17771668 & 3.09088638 & 0.920 \\
\hline & 2 & 31.4520058 & 10.32891615 & 0.85776980 & 30.8363843 & 8.00177988 & 3.02438852 & 0.877 \\
\hline & 3 & 31.1554626 & 10.29381994 & 0.85485522 & 30.6475200 & 8.17395880 & 3.08946603 & 0.898 \\
\hline & 4 & 31.2711453 & 10.34187188 & 0.85884571 & 30.4715129 & 8.29049564 & 3.13351282 & 0.841 \\
\hline & 5 & 31.2027498 & 10.34497031 & 0.85910302 & 30.3944043 & 8.50868609 & 3.21598105 & 0.839 \\
\hline & 6 & 31.1005330 & 10.32576034 & 0.85750772 & 30.3165057 & 8.66131959 & 3.27367109 & 0.844 \\
\hline & 7 & 31.5819366 & 11.55983913 & 0.95999239 & 30.2518243 & 8.78782378 & 3.32148518 & 0.765 \\
\hline & 8 & 31.0323292 & 10.36960425 & 0.86114876 & 30.1991443 & 8.91417439 & 3.36924122 & 0.835 \\
\hline & 9 & 30.9988406 & 10.36905312 & 0.86110299 & 30.1733129 & 9.01785132 & 3.40842742 & 0.836 \\
\hline & 10 & 31.0513794 & 10.40834147 & 0.86436571 & 30.1827486 & 9.11795614 & 3.44626349 & 0.829 \\
\hline $\begin{array}{l}\text { Entropy of } \\
\text { Hdiff }\end{array}$ & 1 & 1.5257865 & 0.10911401 & 0.00906143 & 1.5202071 & 0.07754101 & 0.02930775 & 0.894 \\
\hline
\end{tabular}

The Utilization of Physics Parameter to Classify Histopathology... (Anak Agung Ngurah Gunawan) 


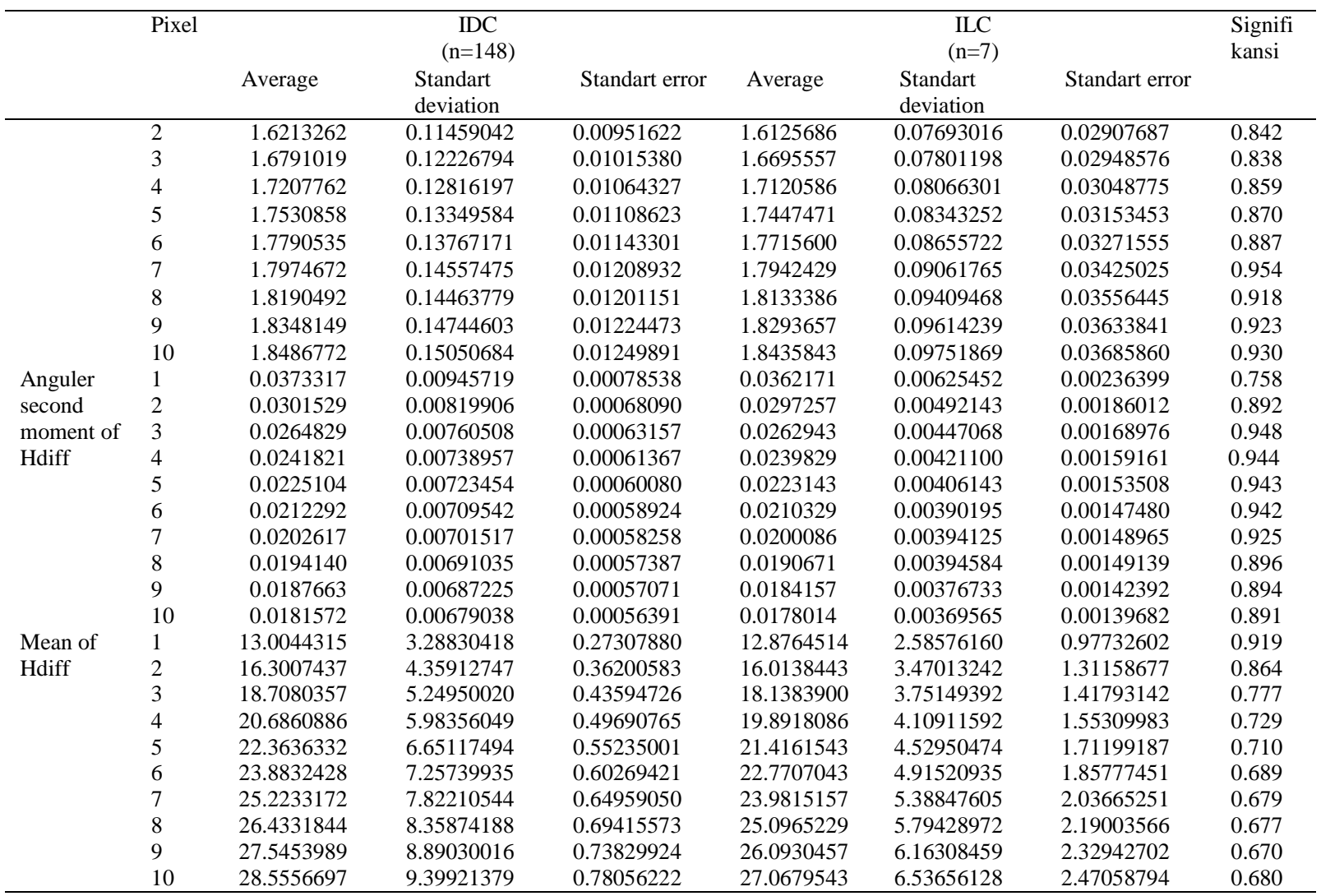

Anova was conducted using IBM SPSS 20 software. The mean parameter is the only parameter that significantly distingguish IDC and ILC. At the mean analyis, the distance of 1-5 pixels are significantly distinguish IDC and ILC, while the higher distances are not sigificantly different.

The decision system of CAD that we developed can fall into one of the four categories. The image area can be called ILC and IDC and a decision can be true or false. The CAD system that we developed can produce two false output types, namely False Positive (FP) and False Negative (FN). True Positive (TP) and True Negative (TN) is the true decision. Two working measurements of classification system which are related with identified decision above are 'Sensitivity and Specificity'. Sensitivity (Recall) is TP/(TP+FN) whereas Specificity is $\mathrm{TN} /(\mathrm{TN}+\mathrm{FP})$. The high values of sensitivity and specificity are very expected. 'Accuracy' and 'Precision' are also used to evaluate the performance of KNN system. Accuracy is $(\mathrm{TN}+\mathrm{TP}) /(\mathrm{TP}+\mathrm{FN}+\mathrm{TN}+\mathrm{FP})$ and Precision is $\mathrm{TP} /(\mathrm{TP}+\mathrm{FP})$. Error Rate is $(\mathrm{FP}+\mathrm{FN}) /(\mathrm{TP}+\mathrm{FN}+\mathrm{TN}+\mathrm{TP})$.

To assess our algorithm, we examined 152 images from the data base of Dokter Soetomo Hospital, Surabaya, Indonesia. 145 (95\%) images have IDC character and 7 (5\%) images have ILC character. The results of our analysis are shown at Table 5.

Table 5 The Result of Analysis

\begin{tabular}{|c|c|c|c|c|}
\hline \multirow[t]{2}{*}{ Performance measure } & \multicolumn{2}{|c|}{$\begin{array}{l}\text { IDC cases } \\
145(95 \%)\end{array}$} & \multicolumn{2}{|c|}{$\begin{array}{c}\text { ILC cases } \\
7(5 \%)\end{array}$} \\
\hline & $\begin{array}{c}\mathrm{TP} \\
102(70 \%)\end{array}$ & $\begin{array}{c}\mathrm{FN} \\
43(30 \%)\end{array}$ & $\begin{array}{c}\mathrm{TN} \\
5(71 \%)\end{array}$ & $\begin{array}{c}\text { FP } \\
2(29 \%)\end{array}$ \\
\hline Sensitivity (Recall) & & & $70 \%$ & \\
\hline Specificity & & & $71 \%$ & \\
\hline Accuracy & & & $70 \%$ & \\
\hline Precision & & & $98 \%$ & \\
\hline Error Rate & & & $30 \%$ & \\
\hline
\end{tabular}

Evaluating of the performance of the CAD system that we developed to classify histopathology types of IDC and ILC needed the definite criteria to determine cluster detection of TP and FP. To evaluate our result, true classification cluster was identified by a radiologist and an expert of Pathology Anatomy. The criteria we used to calculate the number of TP detection, assuming that a detection cluster was true if the 
examination result from the radiologists and the experts of Pathology Anatomy (PA) was the same with the system decision of CAD that we developed. If the decision was assumed to be different, so it was assumed FP.

It was like shown at table 5, our algorithm, the sensitivity was $70 \%$, the specificity was $71 \%$, the accuracy was $70 \%$, the precision was $98 \%$, and error rate was $30 \%$. Two radiologists and experts of pathology and anatomy found our result was quite satisfying and could be reliable.

\section{CONCLUSION}

The CAD system that we developed by using physics parameter was very helpful in classifying histopathology type of breast cancer. Mammogram image was very difficult to detect histopathology types. Even, the Radiology experts were not able to identify it for $100 \%$.

The utilization of physics parameter to classify histopathology types of breast cancer helped the experts of Radiology to get the second opinion. The final aim of the CAD system that we developed for mammography was to detect untouchable lesion which its size was often neglected on mammography. Detection of histopathology type increased the opportunity for women to be successful in the treatment of breast cancer.

Our research was especially focused on histopathology types of IDC and ILC. We used physics parameter to classify histopathology types of breast cancer, after getting significant variable to distinguish histopathology types of IDC and ILC. Then, we used the parameter as the input variable of KNN method to take decision whether it included IDC or ILC histopathology types.

According to the experts of radiology, the result produced by the CAD system that we developed was quite satisfying and could be reliable, and could assist the expert of radiology in diagnosing breast cancer.

\section{ACKNOWLEDGMENTS}

The authors would like to thank for the assistance given during the research to: Directorate of Research and Community Service (DRPM) as the research funder. Prof.Dr.dr.Ketut Suastika,SpPD-KEMD (Rector of Udayana University, Bali), Prof.Dr.Ir. I Nyoman Gde Antara,M.Eng (Chairman of LPPM Udayana University, Bali), Drs. I.B. Suaskara,M.Si (Dean of FMIPA Faculty, Udayana University, Bali), Prof.Dr.dr.Sri Maliawan,SP.BS(K) (Chairman of Research Ethics Commission FK UNUD/RSUP Sanglah, Denpasar), Prof. Dr.dr.Triyono KSP,Sp.Rad( K) (Chairman of Radiology Department of RSUP Dokter Soetomo Hospital, Surabaya), dr. A.A.A.N.Susraini,SpPA(K) (Chairman of Pathology Anatomy Department of RSUP Sanglah Hospital, Denpasar Bali), dr. Bagus G. Dharmawan, Sp.Rad (Chairman of Radiology Department of RSU. Prima Medika Hospital, Denpasar, Bali), Wirabrata (Director of Human Resource and Education of RSUP Sanglah Hospital Denpasar, Bali), dr. Putu Dian Ekawati, MPH (President Director of RSU. Prima Medika Hospital, Denpasar, Bali).

\section{REFERENCES}

[1] Satoko Nakano, Masahiko Ohtsuka, Akemi Mibu, at al., "Diagnostic imaging strategy for MDCT- or MRI-detected breast lesions: use of targeted sonography", BMC Medical Imaging, 201212:13.

[2] Jimmy Okello, Harriet Kisembo, Sam Bugeza, at al., "Breast cancer detection using sonography in women with mammographically dense breasts", BMC Medical Imaging, 201414:41.

[3] Sylvia H. Heywang-Köbrunner, Astrid Hacker, Stefan Sedlacek, "Advantages and Disadvantages of Mammography Screening”, Breast Care (Basel), 2011 Jun, vol. 6, no. 3, pp. 199-207.

[4] Fernanda Philadelpho AP, Gabriela M, Maria Julia GC, at al., "Magnetic resonance imaging-radioguided occult lesion localization (ROLL) in breast cancer using Tc-99m macro-aggregated albumin and distilled water control", BMC Medical Imaging, 201313:33.

[5] Arjan P Schouten van der Velden, Carla Boetes, Peter Bult, at al., "Magnetic resonance imaging in size assessment of invasive breast carcinoma with an extensive intraductal component", BMC Medical Imaging, 20099:5.

[6] Bateman, Timothy, "Advantages and disadvantages of PET and SPECT in a busy clinical practice", Journal of Nuclear Spinger Journal, Jan 19, 2012.

[7] Romualdo Barroso-Sousa and Otto Metsger-Filho, "Difference between invasive lobuler and invasive duktal carcinoma of the breast: result and therapeutic implications", Therapeutic Advances in Medical Oncology, vol. 8 no. 4, pp. 261-266.

[8] Sunil RL., Lan OE., Stuart JS., at al., "WHO Classification of Tumours of The Breast", International Agency for Research on Cancer, $4^{\text {th }}$ Edition, Lyon, 2012.

[9] A.A.N. Gunawan, Supardi, Dharmawan, "Readability Increase Of Mammography X-Ray Photos Results In Determining The Breast Cancer Histopathology Types Using Special Pattern Cropping With Physical Parameter", Advances in Applied Physics, 2014, vol. 2, no. 1, pp. 43-52. 
[10] A.A.N. Gunawan, "A novel model determination of breast cancer stage using physical parameter", Far East Journal of Mathematical Sciences, 2014, vol. 87, no. 1, pp. 23-35.

[11] Dhawan, A.P., "Analysis of Mammofraphic Microcalcification Using Gray Level Image Structure Feature", IEEE,Trans.Medical Imaging, 1996, vol. 15, pp. 246-257.

\section{BIOGRAPHIES OF AUTHORS}
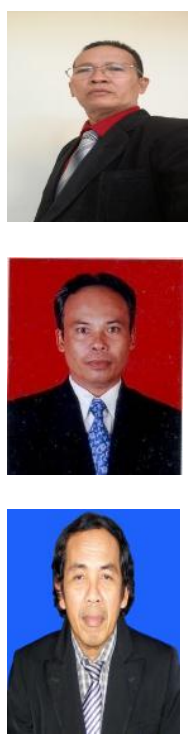

Dr. Anak Agung Ngurah Gunawan, M.T., was born in Denpasar on September 25, 1962. He obtained his Masters degree in 1999 in computer Engineering, Institut Teknologi 10 Nopember Surabaya Indonesia and his Dr degree from the faculty sains and teknologi, University of Airlangga Surabaya Indonesia. His main interess are image procecing. He has published 24 peper in journal international. He is a Senior Lecture Departement of physics University of Udayana at Bali Indonesia.

I Wayan Supardi, S.Si, M.Si. Born on March 31, 1971, undergraduate degree (S1) in 1998, Department of Physics (Physics of Instrumentation of Electronics and Output) Faculty of Mathematics and Natural Sciences Udayana University, Strata 2 (S2) in 2004 Department of Physics (Instrumentation Physics) Bandung Institute of Technology (ITB ). Becoming a Lecturer at Physics Department in 1999. Field of instrumentation and energy penetration.

Ir. S. Poniman, M.Si, born on June 6, 1956, has been a staff of physics faculty of mathematics and natural sciences of udayana university since 1986. Undergraduate degree (S1) at surabaya technological institute in 1985, postgraduate program (S2) Bandung in 1996. Field of superconductor research. The experience of the organization became chairman of the faculty of mathematics faculty of university udayana since 2011 until now. 